\title{
Accounting for phylogenetic relatedness in cross-species analyses of telomere shortening rates
}

\author{
Michael Le Pepke ${ }^{1}$ (D) and Dan T.A. Eisenberg ${ }^{2}$ \\ ${ }^{1}$ Centre for Biodiversity Dynamics (CBD), Norwegian University of Science and Technology (NTNU), Trondheim, Norway, \\ and ${ }^{2}$ Department of Anthropology, University of Washington, Seattle, WA, USA
}

(Received 17 February 2020; Revised 01 April 2020; Accepted 01 April 2020)

\begin{abstract}
Telomeres are repeating DNA sequences found on the ends of chromosomes, which shorten with age and are implicated in senescence. Cross-species analyses of telomere shortening rates (TSR) and telomere lengths are important for understanding mechanisms underlying senescence, lifespan and life-history strategies of different species. Whittemore et al. (2019) generated a new dataset on variation in TSR, lifespan and body mass. In phylogenetically uncorrected analyses they found that TSR negatively correlates with lifespan. We re-ran analyses of their dataset using appropriate phylogenetic corrections. We found a strong phylogenetic signal in the association between TSR and body mass. We were able to corroborate Whittemore et al.'s major findings, including while correcting for body mass in a multivariate analysis. Since laboratory mice have different telomere lengths and potentially different telomere dynamics than wild mice, we removed mice from the analysis, which attenuates most associations.
\end{abstract}

Keywords: lifespan; phylogenetic correction; phylogenetic signal; telomere length; telomere shortening rate

\section{Introduction}

Telomeres are repeating DNA sequences found on the ends of chromosomes which shorten with age and are implicated in senescence. Past studies found that telomeres tend to shorten at faster rates in species with shorter lifespans (Dantzer \& Fletcher, 2015; Haussmann et al., 2003; Tricola et al., 2018). Whittemore et al. (2019), hereafter WEA, recently generated a dataset of cross-sectional telomere shortening rates across nine different tetrapod species using the quantitative fluorescence in situ hybridization technique to measure telomere length. They found a strong negative relationship between telomere shortening rates and lifespan. However, their analyses did not consider the phylogenetic relationships between the species they compared. It is now well established that it is necessary to consider the phylogenetic relationships between species in cross-species analyses (e.g. Garland et al., 2005). Not controlling for the phylogenetic relationship between species implicitly assumes a "star phylogeny" in which all species are equally related to each other or that the traits in question are not influenced by phylogeny (Felsenstein, 1985). Neither of these are usually the case. Here we re-analyze the data from WEA using phylogenetically informed analyses. Our analyses are similar to the recent re-analysis of WEA by Udroiu (2020). Our analysis differs from Udroiu's in two key ways. First, instead of independent contrasts and analyses of residuals we use phylogenetic generalized least squares (PGLS) regression with multivariate analyses. Second, we exclude the laboratory mouse in some of our analyses out of concern that laboratory mice have been shown to have considerably longer telomeres than their wild counterparts possibly due to artificial selection and/or inbreeding (Eisenberg, 2011; Kotrschal et al., 2007; Manning et al., 2002; Weinstein \& Ciszek, 2002). 


\section{Objective}

While we appreciate these new data generated by WEA, and the questions they address with these data, we have concerns about their statistical techniques and inclusion criteria. We elaborate these concerns and discuss re-analyses of the data using appropriate phylogenetic corrections and exclusion of the laboratory mouse below.

\section{Methods}

We compiled species-level phylogenetic trees from sources reported in the supporting information. This supporting information also contains further details on the methods briefly described below. We reconstructed a time-calibrated supertree, which was pruned to match the species in WEA. We used PGLS (Grafen, 1989) to test linear correlations between lifespan, telomere shortening rate (TSR), initial telomere length (TL), body mass and heart rate following WEA. Most data are log-transformed for normalization, but we also include some analyses of the non-transformed data for comparison with WEA. We estimated Pagel's $\lambda$ with default bounds (0-1) using maximum likelihood.

\section{Results}

As illustrated in Figure 1, the species in question lie in two distinct groups, which can create a "worst case" scenario for cross-species analysis (Felsenstein, 1985). Re-analyzing the primary findings from WEA (their Figures 2, S1, \& S2) with appropriate phylogenetic regressions leaves the general findings of WEA intact (Table 1). However, we find a strong phylogenetic association between body mass and TSR (Pagel's $\lambda=0.97$ ), but not among the other associations in Table 1 . Re-analyzing the WEA dataset with phylogenetic corrections and excluding the laboratory mouse (C57BL/6 strain) weakens all results (Table 1). While the key association between TSR and lifespan remains in the same direction and significant, the magnitude of the effect is attenuated. The multivariate analyses of lifespan in WEA (their Tables S5 and S6) includes both body mass and heart rate, which strongly correlate $\left(R^{2}=0.94, p<0.0001\right)$. WEA found that TSR, initial TL, body mass and heart rate all significantly correlate with average lifespan. To avoid multicollinearity, we excluded heart rate from the phylogenetic multivariate models, which show that only TSR significantly predicts average and maximum lifespan (Table 2). Excluding the mouse samples strengthens the positive association of initial TL with maximum lifespan.

\section{Discussions}

Telomere shortening across species has been shown to be strongly influenced by phylogeny in birds (Tricola et al., 2018) and telomere length to be strongly influenced by phylogeny in mammals

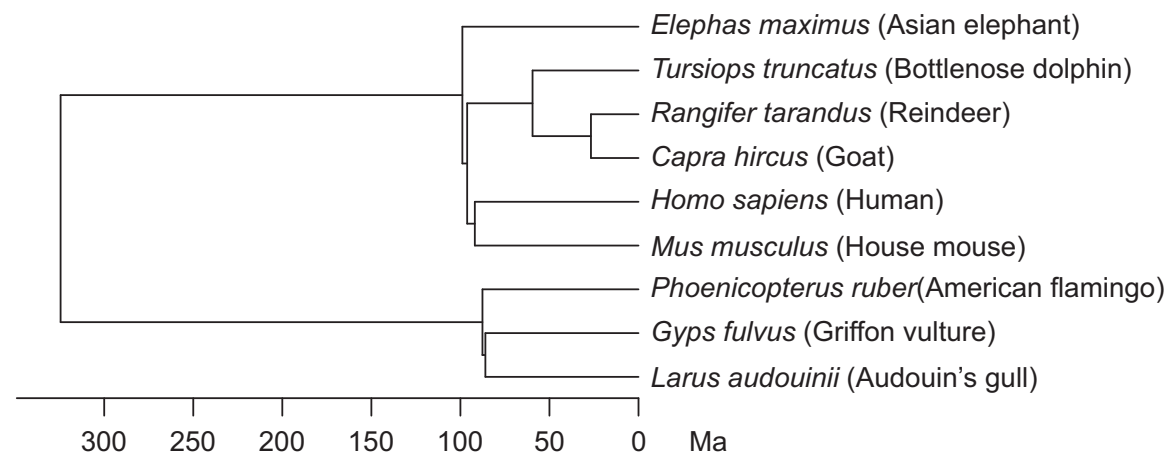

Figure 1. Phylogenetic relationships between species compared in Whittemore et al. (2019) with a time scale in million years ago (Ma). 
Table 1. Results of non-phylogenetic (corresponding to Whittemore et al., 2019) and phylogenetic corrected regressions between species traits with and without the inbred laboratory mouse. Figure references are to figures in Whittemore et al. (2019).

\begin{tabular}{|c|c|c|c|c|c|c|}
\hline & \multicolumn{2}{|c|}{$\begin{array}{l}\text { Non-phylogenetic } \\
\text { regression } \\
\text { (9 species) }\end{array}$} & \multicolumn{2}{|c|}{$\begin{array}{l}\text { Phylogenetic } \\
\text { regression } \\
\text { (9 species) }\end{array}$} & \multicolumn{2}{|c|}{$\begin{array}{l}\text { Phylogenetic } \\
\text { regression without } \\
\text { mouse (8 species) }\end{array}$} \\
\hline & $\mathrm{R}^{2}$ & p-value & $\mathrm{R}^{2}$ & p-value & $\mathrm{R}^{2}$ & p-value \\
\hline $\log$ (body mass) vs. $\log ($ TSR). (Fig. S1) & 0.413 & 0.062 & 0.623 & $0.011^{*}$ & 0.081 & 0.495 \\
\hline $\log$ (heart rate) vs. $\log (\mathrm{TSR})$. (Fig. S2) & 0.540 & $0.038^{*}$ & 0.540 & $0.038^{*}$ & 0.008 & 0.849 \\
\hline max. lifespan vs. initial TL. (Fig. 2A) & 0.019 & 0.724 & 0.019 & 0.724 & 0.001 & 0.948 \\
\hline $\log (\max$. lifespan) vs. $\log$ (initial TL). (Fig. 2B) & 0.041 & 0.603 & 0.041 & 0.603 & 0.021 & 0.730 \\
\hline av. lifespan vs. initial TL. (Fig. 2C) & 0.125 & 0.350 & 0.125 & 0.350 & 0.077 & 0.507 \\
\hline log(av. lifespan) vs. log(initial TL). (Fig. 2D) & 0.145 & 0.313 & 0.145 & 0.313 & 0.029 & 0.688 \\
\hline $\log (\max$. lifespan) vs. $\log (\mathrm{TSR})$. (Fig. 2E) & 0.829 & $0.0006^{\star \star *}$ & 0.829 & $0.0006^{\star \star \star}$ & 0.581 & $0.030^{*}$ \\
\hline $\log$ (av. lifespan) vs. $\log (T S R)$. (Fig. 2G) & 0.934 & $0.00002^{\star \star \star}$ & 0.934 & $0.00002^{\star \star \star}$ & 0.839 & $0.0014^{\star *}$ \\
\hline
\end{tabular}

${ }^{\star} \mathrm{p}<0.05,{ }^{\star \star} \mathrm{p}<0.01,{ }^{\star \star \star} \mathrm{p}<0.001$

Table 2. Phylogenetic multivariate analyses of average and maximum lifespan, respectively, versus TSR, initial TL and body mass with (w.) and without (w/o) the mouse samples.

\begin{tabular}{|c|c|c|c|c|c|c|c|c|}
\hline $\begin{array}{l}\text { Response: } \log (\text { av. } \\
\text { lifespan) }\end{array}$ & $\begin{array}{l}\beta \text { with } \\
\text { mouse }\end{array}$ & $\begin{array}{l}\beta w / o \\
\text { mouse }\end{array}$ & $\begin{array}{l}\text { S.E. w. } \\
\text { mouse }\end{array}$ & $\begin{array}{l}\text { S.E. w/o } \\
\text { mouse }\end{array}$ & $\begin{array}{l}\text { t-val. } \\
\text { w. } \\
\text { mouse }\end{array}$ & $\begin{array}{l}\text { t-val. } \\
\text { w/o } \\
\text { mouse }\end{array}$ & $\begin{array}{l}\text { p-value } \\
\text { w. mouse }\end{array}$ & $\begin{array}{l}\text { p-value } \\
\text { w/o } \\
\text { mouse }\end{array}$ \\
\hline Intercept & 3.027 & 2.839 & 0.292 & 0.289 & 10.38 & 9.836 & $0.00014^{\star \star *}$ & $0.00060^{\star \star *}$ \\
\hline $\log (T S R)$ & -0.807 & -0.714 & 0.116 & 0.121 & -6.934 & -5.915 & $0.00096^{\star \star \star}$ & $0.00409^{\star *}$ \\
\hline $\log ($ initial TL) & 0.274 & 0.284 & 0.192 & 0.171 & 1.431 & 1.659 & 0.21197 & 0.17249 \\
\hline $\log$ (mass) & -0.001 & -0.025 & 0.040 & 0.039 & -0.031 & -0.650 & 0.97680 & 0.55136 \\
\hline \multicolumn{9}{|l|}{$\log (\max$. lifespan) } \\
\hline Intercept & 2.664 & 2.693 & 0.327 & 0.318 & 8.134 & 8.464 & $0.00046^{\star \star \star}$ & $0.00107^{\star \star}$ \\
\hline $\log (T S R)$ & -0.748 & -0.777 & 0.131 & 0.144 & -5.725 & -5.406 & $0.00228^{\star \star}$ & $0.00567^{\star \star}$ \\
\hline $\log$ (initial TL) & 0.536 & 0.692 & 0.215 & 0.164 & 2.491 & 4.223 & 0.05508 & $0.01344^{*}$ \\
\hline $\log$ (mass) & 0.009 & -0.117 & 0.045 & 0.072 & 0.211 & -1.618 & 0.84108 & 0.18100 \\
\hline
\end{tabular}

${ }^{\star} p<0.05,{ }^{\star *} p<0.01,{ }^{\star \star *} p<0.001$

(Gomes et al., 2011). Particularly concerning is the fact that a past study suggests that telomeres might lengthen with age in wild mice (Ilmonen et al., 2008), which can live longer than laboratory mice (Miller et al., 2002). However, we find that corrections for phylogeny and excluding the potentially problematic laboratory mouse does not substantively alter the general findings of WEA's analysis.

\section{Conclusions}

Together with past analyses of lifespan and TSR (Dantzer \& Fletcher, 2015; Haussmann et al., 2003; Tricola et al., 2018) and another re-analysis of WEA (Udroiu, 2020), it is clear that species with more 
rapid TSR tend to have shorter lifespans even when correcting for body mass. Nonetheless, we think it is important to share our re-analyses to help assure others with the same concerns about the WEA analysis we raised, to serve as a reminder of the importance of best practices in cross-species analyses, and to provide more reliable estimates of the associations in question.

Acknowledgements. We thank editor Reinder Radersma and two reviewers for valuable comments on a previous version of this manuscript.

Conflicts of Interest. None.

Author Contributions. M.L.P. analyzed the data and both authors wrote the paper.

Funding Information. M.L.P. is supported by the Research Council of Norway through its Centres of Excellence funding scheme (223257). The authors declare no competing interests.

Data Availability Statement. All species trait data is available in the online supporting information in Whittemore et al. (2019). Phylogenetic data can be accessed through the sources provided in the supporting information for this study.

Supplementary Materials. To view supplementary material for this article, please visit http://dx.doi.org/10.1017/exp.2020.18.

\section{References}

Dantzer, B., \& Fletcher, Q. E. (2015). Telomeres shorten more slowly in slow-aging wild animals than in fast-aging ones. Experimental Gerontology, 71, 38-47.

Eisenberg, D. T. A. (2011). An evolutionary review of human telomere biology: The thrifty telomere hypothesis and notes on potential adaptive paternal effects. American Journal of Human Biology, 23, 149-167.

Felsenstein, J. (1985). Phylogenies and the comparative method. The American Naturalist, 125, 1-15.

Garland, T., Bennett, A. F., \& Rezende, E. L. (2005). Phylogenetic approaches in comparative physiology. Journal of Experimental Biology, 208, 3015.

Gomes, N. M., Ryder, O. A., Houck, M. L., Charter, S. J., Walker, W., Forsyth, N. R., Austad, S. N., Venditti, C., Pagel, M., Shay, J. W., \& Wright, W. E. (2011). Comparative biology of mammalian telomeres: Hypotheses on ancestral states and the roles of telomeres in longevity determination. Aging Cell, 10, 761-768.

Grafen, A. (1989). The phylogenetic regression. Philosophical Transactions of the Royal Society B, 326, 119-157.

Haussmann, M. F., Winkler, D. W., O'Reilly, K. M., Huntington, C. E., Nisbet, I. C. T., \& Vleck, C. M. (2003). Telomeres shorten more slowly in long-lived birds and mammals than in short-lived ones. Proceedings of the Royal Society of London. Series B: Biological Sciences, 270, 1387-1392.

Ilmonen, P., Kotrschal, A., \& Penn, D. J. (2008). Telomere attrition due to infection. PLoS One, 3, e2143.

Kotrschal, A., Ilmonen, P., \& Penn, D. J. (2007). Stress impacts telomere dynamics. Biology Letters, 3, 128-130.

Manning, E. L., Crossland, J., Dewey, M. J., \& Van Zant, G. (2002). Influences of inbreeding and genetics on telomere length in mice. Mammalian Genome, 13, 234-238.

Miller, R. A., Harper, J. M., Dysko, R. C., Durkee, S. J., \& Austad, S. N. (2002). Longer life spans and delayed maturation in wild-derived mice. Experimental Biology and Medicine, 227, 500-508.

Tricola, G., Simons, M. J. P., Atema, E., Boughton, R. K., Brown, J. L., Dearborn, D. C., Divoky, G., Eimes, J. A., Huntington, C. E., Kitaysky, A. S., Juola, F. A., Lank, D. B., Litwa, H. P., Mulder, E. G. A., Nisbet, I. C. T., Okanoya, K., Safran, R. J., Schoech, S. J., Schreiber, E. A., \& Haussmann, M. F. (2018). The rate of telomere loss is related to maximum lifespan in birds. Philosophical Transactions of the Royal Society B: Biological Sciences, 373, 20160445.

Udroiu, I. (2020). On the correlation between telomere shortening rate and life span. Proceedings of the National Academy of Sciences, 117, 2248.

Weinstein, B. S., \& Ciszek, D. (2002). The reserve-capacity hypothesis: Evolutionary origins and modern implications of the trade-off between tumor-suppression and tissue-repair. Experimental Gerontology, 37, 615-627.

Whittemore, K., Vera, E., Martínez-Nevado, E., Sanpera, C., \& Blasco, M. A. (2019). Telomere shortening rate predicts species life span. Proceedings of the National Academy of Sciences, 116, 15122.

Cite this article: Pepke ML, Eisenberg DTA (2020). Accounting for phylogenetic relatedness in cross-species analyses of telomere shortening rates Experimental Results, 1, e11, 1-7. https://doi.org/10.1017/exp.2020.18 


\section{Peer Reviews}

\section{Reviewing editor: Dr. Reinder Radersma}

Wageningen University and Research, Plant Sciences, Droevendaalsesteeg 1, Wageningen, Netherlands, 6708 PB

This article has been accepted because it is deemed to be scientifically sound, has the correct controls, has appropriate methodology and is statistically valid, and met required revisions.

doi:10.1017/exp.2020.18.pr 1

\section{Review 1: Accounting for phylogenetic relatedness in cross-species analyses of telomere shortening rates}

Reviewer: Dr. Ion Udroiu

Date of review: 27 February 2020

Published online:

(c) The Author(s) 2020 This is an Open Access article, distributed under the terms of the Creative Commons Attribution licence (http://creativecommons.org/licenses/by/4.0/), which permits unrestricted re-use, distribution, and reproduction in any medium, provided the original work is properly cited.

Conflict of interest statement. I have recently published a similar article. I do not know if it is a conflict of interest.

Dear Editor,

I have some concerns that I put to your attention. I have no major observations on the manuscript per se. The problems are the original data from the article of Whittemore et al. (2019) and the fact that I recently published a similar article.

The authors correctly underline that interspecies comparison must be analysed with phylogenetic corrections. Nonetheless, some quantities are redundant (such as heart rate, which is inversely proportional to mass), other ones are improper and never used in these studies ("average" lifespan, which, by the way is also proportional to maximum lifespan, therefore redundant) and the data are inhomogeneous: some species comprise only adult, other ones adult+infant (this is important because telomeres shorten more rapidly in infants). Some of these problems have been raised in my letter (Udroiu, I. 2020. On the correlation between telomere shortening rate and life span. PNAS, 117, 2248-2249). I have not mentioned it in the Comments to the Author, as I do not want to be a reviewer that asks for citations of its own articles. By the way, if you consider it appropriate you could suggest it to the authors. Finally, since my article made essentially the same analyses made in the present manuscript, I do not know if this lack of originality is a problem for its acceptance.

Comments to the Author: The paper correctly starts from the fact that interspecies comparison must be analysed with phylogenetic corrections, and uses a phylogenetic generalized least squares method to re-analyse data from Whittemore et al. (2019). The article is simple and clear and I have only minor concerns. 1) Analyses made by the authors: data are log-transformed, which is correct (and this was not done by Whittemore et al.). Why do the authors have used also non-transformed data? Since lifespan and heart rate are directly and inversely correlated with body mass, all analyses could be redundant. In this case, analyses of residuals are usually performed, e.g.: mass against lifespan, I get residual lifespan and the I test correlation between residual lifespan and telomeres. 2) Original data: Average lifespan is a quite bizarre quantity in my view: in the best case it is redundant with maximum lifespan. Data are inhomogeneous: some species comprise only adult, other ones adult+infant (this is important because telomeres shorten more rapidly in infants). Data for lifespans (and perhaps body mass) should be checked: e.g., value for Phoenicopterus ruber is 60 years, while in Anage (the source cited by Whittemore et al.) it is reported as "Not yet established" (and it reports 44 years for Phoenicopterus roseus and 36.7 years for Phoenicopterus chilensis...). 3) Considerations of the authors: In my view, the authors correctly excluded laboratory mouse. Indeed, data for telomeres are from laboratory mice, but the record of max. lifespan is from a population of feral mice (see Anage), which usually have much shorter telomeres (12 kb like humans). 
Is the data presented in the most useful manner? (40\%) 3/5

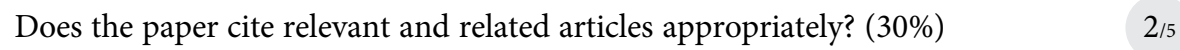

\section{Context}

Does the abstract correctly embody the content of the article? (25\%)

Does the introduction give appropriate context? (25\%)

Is the objective of the experiment clearly defined? (25\%)

Analysis

Are the limitations of the experiment as well as the contributions of the experiment clearly outlined? $(20 \%)$ 


\section{Review 2: Accounting for phylogenetic relatedness in cross-species analyses of telomere shortening rates}

\section{Reviewer: Miss Gianna Tricola (D)}

National Institute of Diabetes and Digestive and Kidney Diseases, Lab of Cell and Molecular Biology, 8 Center Dr., Bethesda, Maryland, United States, 20892-0001

Date of review: 12 March 2020

Published online:

(c) The Author(s) 2020 This is an Open Access article, distributed under the terms of the Creative Commons Attribution licence (http://creativecommons.org/licenses/by/4.0/), which permits unrestricted re-use, distribution, and reproduction in any medium, provided the original work is properly cited.

Conflict of interest statement. Reviewer declares none.

Comments to the Author: The authors conduct appropriate phylogenetic correction for a previous report (Whittemore et. al., 2019) to address the lack of such consideration in the relationship between telomere shortening rates (TSR) and lifespan in phylogenetically distant species. However, in order to mitigate model selection, phylogenetic correction should be included for the multivariate linear regressions using TSR, TL, body mass, and heart rate fit to average and maximum lifespans (Tables S5 and S6). This analysis will create a more robust argument for the role of TSR in determining lifespan since these other variables may contribute to the relationship. I suggest rewording the sentence in lines 16-18 of the abstract. More explicitly state the findings of Whittemore et. al., 2019 before mentioning how your additional analyses either did or did not change those findings. It may help to divide this into two different sentences, one per finding.

\section{Score Card}

Presentation

Is the data presented in the most useful manner? (40\%)

Does the paper cite relevant and related articles appropriately? (30\%)

\section{Context}

5.0

Does the title suitably represent the article? (25\%)

Does the abstract correctly embody the content of the article? (25\%)

Does the introduction give appropriate context? (25\%)

Is the objective of the experiment clearly defined? (25\%)

Are the limitations of the experiment as well as the contributions of the experiment clearly outlined? $(20 \%)$ 